02ICES-147

\title{
Analysis and Design of Crew Sleep Station for ISS
}

\author{
John F. Keener, Thomas Paul and Bradley Eckhardt \\ Lockheed Martin Space Operations \\ Fredrick Smith \\ NASA Johnson Space Center
}

\begin{abstract}
This paper details the analysis and design of the Temporary Sleep Station (TeSS) environmental control system for International Space Station (ISS). The TeSS will provide crewmembers with a private and personal space, to accommodate sleeping, donning and doffing of clothing, personal communication and performance of recreational activities. The need for privacy to accommodate these activities requires adequate ventilation inside the TeSS. This study considers whether temperature, carbon dioxide, and humidity within the TeSS remain within crew comfort and safety levels for various expected operating scenarios.
\end{abstract}

Evaluation of these scenarios required the use and integration of various simulation codes. An approach was adapted for this study, whereby results from a particular code were integrated with other codes when necessary. Computational Fluid Dynaimics (CFD) methods were used to evaluate the flow field inside the TeSS, from which local gradients for temperature, velocity, and species concentration such as $\mathrm{CO}_{2}$ could be determined. A model of the TeSS, containing a human, as well as equipment such as a laptop computer, was developed in FLUENT, a finite-volume code. Other factors, such as detailed analysis of the heat transfer through the structure, radiation, and air circulation from the TeSS to the US Laboratory Aisle, where the TeSS is housed, were considered in the model. A complimentary model was developed in G189A, a code which has been used by NASA/JSC for environmental control systems analyses since the Apollo program.. Boundary conditions were exchanged between the FLUENT and G189A TeSS models. G189A provides human respiration rates to the FLUENT model, while the FLUENT model provides local convective heat transfer coefficients to G189A model. An additional benefit from using an approach with both a systems simulation and CFD model, is the capability to verify the results of each model by comparison to the results of the other model. The G189A and FLUENT models were used to evaluate various ventilation designs for the TeSS over a range of operating conditions with varying crew metabolic load, equipment operating modes, ventilation flow rates, and with the TeSS doors open and closed. Results from the study were instrumental in the optimization of a design for the TeSS ventilation hardware.

A special case was considered where failure of the TeSS ventilation system occurred. In this case, a study was conducted in order to determine the time required for the $\mathrm{CO}_{2}$ concentration inside the TeSS to increase to ISS limit values under transient conditions. A lumped-capacitance code, SINDAFLUINT was used in this case to provide accurate predictions of the human reaction to the TeSS cabin conditions including core and skin temperatures and body heat storage. A simple two-dimensional CFD model of a crewmember inside the TeSS was developed in FLUENT in order to determine the volume envelope of the respired air from the human, which maintained a minimum velocity profile. This volume was then used in the SINDA-FLUINT model to facilitate the calculations of $\mathrm{CO}_{2}$ concentrations, dry bulb temperatures and humidity levels inside the TeSS. 


\section{List of Acronyms}

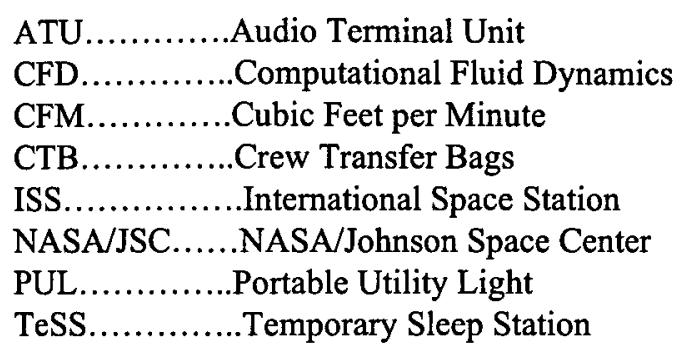

\section{Introduction}

Prior to the installation of the Habitation Module on the International Space Station (ISS) there is no provision for personal space. To accommodate this personal space a design and development effort was undertaken for the Temporary Sleep Station (TeSS). The TeSS was designed for installation in one of the rack volumes in the Laboratory Module (LAB). The TeSS will provide crewmembers with a private and personal space, to accommodate sleeping, donning and doffing of clothing, personal communication and performance of recreational activities. The need for privacy to accommodate these activities requires adequate ventilation and audible caution \& warning notification inside the TeSS.

The design of the TeSS was derived from the Deployable Crew Quarters concept but with a simpler installation. The major differences were in the launch packaging and the attachment of the acoustic insulation. The delivery of the TeSS was in the MPLM on assembly flight 7A.1.

This paper discusses the design and analysis to satisfy certification requirements for the TeSS. The major effort was in determination of crew comfort and safety as related to flow, temperature, humidity and carbon dioxide control. The next sections discuss the requirements for TeSS and how they were satisfied.

\section{TeSS ECLS MISSION REQUIREMENTS}

A simple set of TeSS mission requirements has been documented in order to bound the design process for all major vehicle subsystems. The TeSS mission requirements, which drive the ECLS design, are listed below:

- Power approximately 200W (Laptop and PUL)
- Crew Size $=1$

- Single fault tolerance

- Ventilation flow from CCAA = Crew adjustable from 10 to $50 \mathrm{CFM}$

- Supply air conditions $55^{\circ} \mathrm{F}$ from CCAA

- Metabolic rate hot case determined by "cool down" from exercise. Cold case determined by the small crew sleeping condition.

Separate models of the TeSS were developed using G-189A, a systems simulation code developed by NASA, and FLUENT, a finite-volume code (1). Separate models were developed in order to utilize features in each code, which were not available in the other software. For example, G-189A utilizes the 41Node Transient Metabolic Man subroutine (2) to determine human metabolic and respiration rates under various scenarios for TeSS, but G-189A assumes perfect mixing of the air within the TeSS compartment. The FLUENT TeSS model requires the human metabolic and respiration rates, which are predicted by G-189A, as boundary conditions, but does not assume perfect mixing. FLUENTcan predict local gradients within the TeSS for parameters such as temperature, species concentration, and velocity magnitude. Simulation of transient operating conditions is also more viable in regards to computer run time in the G-189A model of the TeSS in comparison to the FLUENT model. Seven cases were analyzed varying human metabolic loads, supply airflow rates, equipment operating options, and TeSS geometry configurations. Steady-state conditions were assumed in the FLUENT model, whereas transient conditions were simulated in the G-189A model. The analyses using G-189A and FLUENT will be discussed separately.

\section{G-189A Analyses}

The design of the TeSS required the determination of acceptable flow rates in terms of $\mathrm{CO}_{2}$ concentration and air temperature. Based on previous work with the crew quarters and the waste and hygiene compartment $(3,4)$, it was deemed appropriate to utilize the G-189A (5) software for this purpose.

G-189A is a system level analysis tool that assumes uniform temperatures and species concentrations within an enclosure. Construction of the model consists of defining several components along a flow path, and then solving them in a sequential manner. G189A can perform transient simulations with variable heat loads or boundary 
conditions in a short time, which is an advantage when trying to model the effects of changing multiple parameters. The G189A model discussed here consisted of a cabin component, a fan component to vary air flow rates, and a metabolic man component based upon the 41-node man program. The program can solve for the cabin conditions and the sensible and latent heat rejected from the crew based on the cabin conditions. There are also mechanisms for imposing both steady state and transient boundary conditions on the compartment.

The G-189A models used the same boundary conditions listed in Table 1 for both cases analyzed here. G-189A modeled a transient Exercise/Nominal case in which a crewmember is exercising outside of TeSS and then enters TeSS, at which time the crew metabolic rate is ramped down linearly from an exercise level of 500 watts to 137 watts (nominal) over a 15-minute period. This is referred in Table 2 as Case G5. For this case the air flow rate was set at $50 \mathrm{CFM}$ and heat loads from the Portable Utility Light (PUL) and laptop computer were added directly to the cabin air. The second case analyzed began with the crewman outside of TeSS at a nominal metabolic rate of 137 Watts, and then this crewman enters the TeSS and the metabolic rate is ramped down linearly from 137 to 82 Watts, which was used as the sleep metabolic rate. This case is referred to as Case G3 in Table 2. The air flow rate for this case was $10 \mathrm{CFM}$, and the PUL and laptop are not functioning during sleep, so there were no heat loads added from these components. A G-189A analysis was also performed with the crewman inside TeSS at a constant high metabolic rate of 500 Watts and an air flow of 50 CFM with the doors closed. This case is referred to as Case G7 in Table 2.

Table 1. Boundary Conditions for TeSS FLUENT and G-189A models.

TESS Inlet Conditions:

Inlet air Temperature

Inlet air Dew Point Temperature

Inlet air $\mathrm{CO}_{2}$

Inlet air flow rate

Inlet air flow distribution
English Units

$55^{\circ} \mathrm{F}$
$50^{\circ} \mathrm{F}$
$41(\mathrm{~mole} \%)$
$10 \mathrm{CFM}$
$50 \mathrm{CFM}$

Directional flow specified by NASA
SI Units

$$
12.77^{\circ} \mathrm{C}
$$

$10.00^{\circ} \mathrm{C}$

$3.1 \mathrm{mmHg}$ $.28 \mathrm{~m}^{3} / \mathrm{min}$ $1.41 \mathrm{~m}^{3} / \mathrm{min}$

ISS LAB Aisle air supply (CFD model only) :

Inlet air Temperature

Inlet air Dew Point Temperature

Inlet air $\mathrm{CO}_{2}$

Inlet air Flowrate
$75^{\circ} \mathrm{F}$
$50^{\circ} \mathrm{F}$
0.41 (mole \%)
$23.88^{\circ} \mathrm{C}$
$10.00^{\circ} \mathrm{C}$
$3.1 \mathrm{mmHg}$

Hot case - 50 CFM $\times 5$ inlets $\left(1.41 \mathrm{~m}^{3} / \mathrm{min} \times 5\right.$ inlets $)$

Cold case - 58 CFM x 5 inlets $\left(1.64 \mathrm{~m}^{3} / \mathrm{min} \times 5\right.$ inlets $)$

Equipment Heat Loads and Flow Rates:

Portable Utility Light (PUL)

PUL Fan flow

Laptop computer

Laptop Fan flow
327.85 Btu/hr

18.7 CFM

409.82 Btu/hr

$12.3 \mathrm{CFM}$

$1707.59 \mathrm{btu} / \mathrm{hr}$

$467.87 \mathrm{btu} / \mathrm{hr}$

$280.04 \mathrm{btu} / \mathrm{hr}$
96 watts

$.52 \mathrm{~m}^{3} / \mathrm{min}$

120 watts

$.28 \mathrm{~m}^{3} / \mathrm{min}$

Human Metabolic Models:

High metabolic rate

Nominal metabolic rate

Sleep metabolic rate
500 watts

137 watts

82 watts

Wall Modeling: 
Wall thickness:

Wall thermal conductivity:

TeSS wall outer boundary temperature:
.07 feet

$.0074 \mathrm{Btu} / \mathrm{hr}-\mathrm{ft}-\mathrm{F}$

$.0079 \mathrm{Btu} / \mathrm{hr}-\mathrm{ft}-\mathrm{F}$

$75^{\circ} \mathrm{F}$
$.024 \mathrm{~m}$

$.01283 \mathrm{~W} / \mathrm{m}-\mathrm{K}$

$.01382 \mathrm{~W} / \mathrm{m}-\mathrm{k}$ (back wall)

$23.88^{\circ} \mathrm{C}$

Table 2. G189 and FLUENT Case Matrix ${ }^{1}$

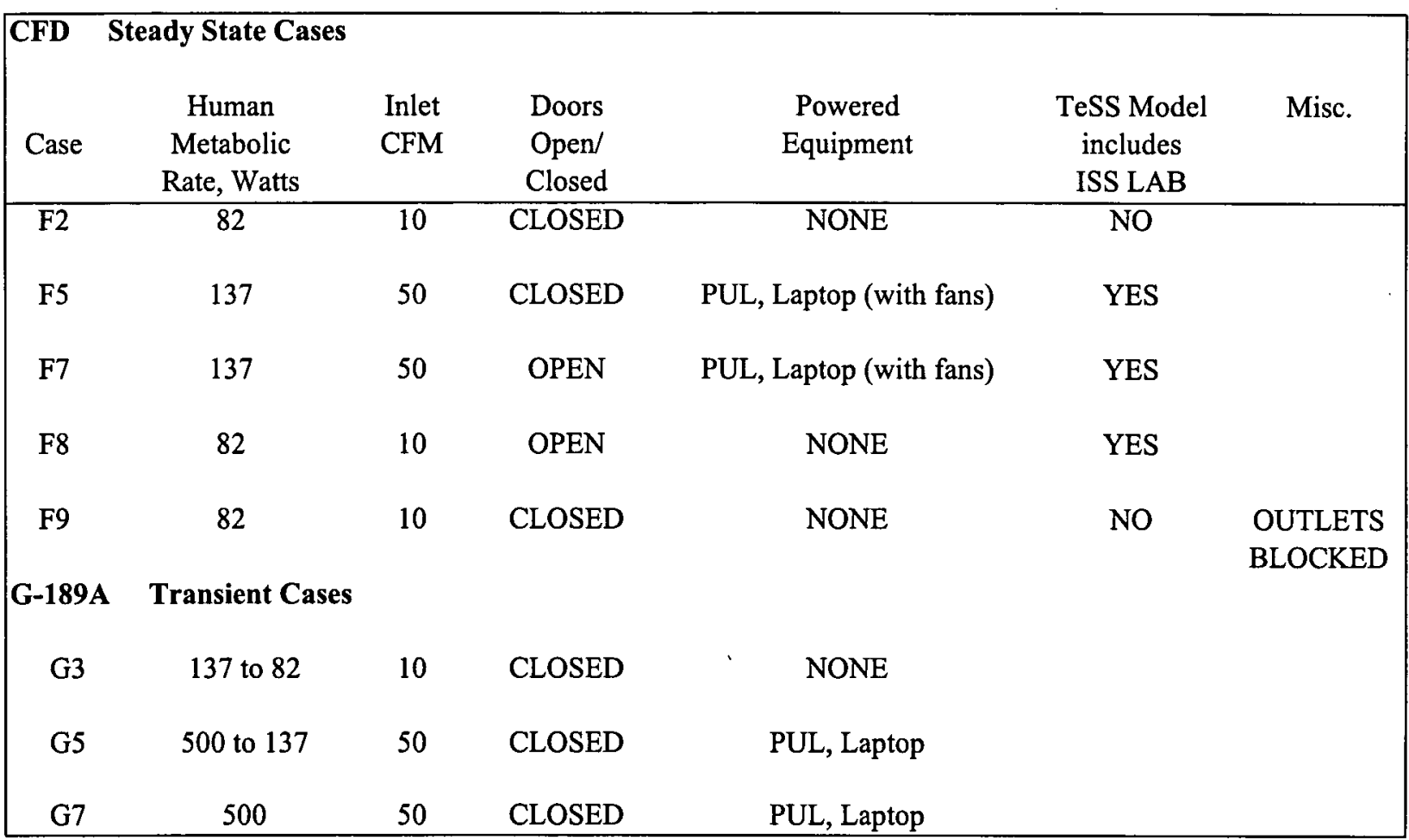

\section{G-189A Results}

Results for cases G3 and G5 are shown in Table 3. The temperatures and $\mathrm{CO}_{2}$ concentrations shown are for the end of the simulation when conditions have reached steady state. For case G3 this would correspond to a crewman inside TeSS at a sleep metabolic rate and for case G5 this would correspond to the steady state conditions for a crewman inside TeSS at a nominal metabolic rate.

Metabolic rates were based upon data from:

2) ASHRAE Handbook, Fundamentals Volume, 1989

3) "Matching Crew Diet and Crop Food Production in BioPlex"

4) Shuttle Operational Databook
Transient temperature and dew point results for case $\mathrm{G} 5$ are shown in Figure $\mathrm{XX}$, and transient $\mathrm{CO}_{2}$ concentration profile are shown in Figure $\mathrm{XX}$. Temperature, dew point temperature, and $\mathrm{CO}_{2}$ levels all increase at $\mathrm{T}=8 \mathrm{hr}$ when the crewman enters TeSS. After this brief increase the values reach a steady state within approximately 30 minutes.

While Results for case G7 are not realistic in the sense that the crewman will not be exercising in TeSS, the results indicate that the dry bulb temperature and $\mathrm{CO}_{2}$ concentration remain within an 
acceptable range. Both G-189A cases indicate that with 10 CFM during sleep and with 50 CFM during nominal activities the dry bulb temperature, dew point temperature, and $\mathrm{CO}_{2}$ concentrations are at levels that would be considered comfortable.

Table 3. Results for TeSS FLUENT and G-189A models Cases.

CFD Steady State Cases

\begin{tabular}{ccccccc} 
Case & $\begin{array}{c}\text { Avg. TESS } \\
\text { Temperature } \\
\text { F }\end{array}$ & $\begin{array}{c}\text { Avg. TESS } \\
\mathrm{PPCO}_{2} \\
\mathrm{MmHg}\end{array}$ & $\begin{array}{c}\text { Avg. TESS } \\
\text { Dew Point } \\
\text { F }\end{array}$ & $\begin{array}{c}\text { Avg. TESS } \\
\text { Air Velocity } \\
\text { feet/min }\end{array}$ & $\begin{array}{c}\text { \% Volume } \\
<7 \mathrm{fpm}\end{array}$ & $\begin{array}{c}\text { \% Volume } \\
>200 \mathrm{fpm}\end{array}$ \\
\hline F2 & 71.7 & 3.8 & 56.7 & 3.1 & & \\
F5 & 71.2 & 3.29 & 53.6 & 28.2 & $7.10 \%$ & $2.90 \%$ \\
F7 & 72.5 & 3.19 & 52.5 & 27.3 & $8.70 \%$ & $2.90 \%$ \\
F8 & 75.1 & 3.15 & 51.9 & 12.5 & & \\
F9 & 74.9 & 3.39 & 53.7 & 2.72 & &
\end{tabular}

G-189A Transient Cases

$\begin{array}{lllll}\text { G3 } & 70.8 & 3.8 & 55.7 & \text { N/A } \\ \text { G5 } & 73.5 & 3.3 & 52.2 & \text { N/A } \\ \text { G7 } & 76.8 & 3.9 & 65.9 & \text { N/A }\end{array}$

\section{G189 / CFD Data Interaction}

Both the G189A and the CFD models described in the next section shared some boundary conditions. Because the CFD software did not have the capability to determine the crew response to the TeSS cabin conditions, the crew metabolic inputs were determined from the G189A results and these were input as boundary conditions on the CFD human surface. This resulted in the crew sensible heat input applied as a heat flux boundary condition on the human surface, and the moisture or latent heat load was applied as a water vapor mass flow inlet on a small surface located on the face of the human. $\mathrm{CO}_{2}$ was also added as a mass flow inlet on the same face surface.

Data from the CFD analyses was also used in the G189A models. Because G189A does not have the ability to calculate surface heat transfer coefficients based upon the flow field, the G189A inner wall heat transfer conductance was based upon the average heat transfer coefficient calculated in the CFD model.

\section{TeSS FLUENT Model}

The FLUENT model uses computational fluid dynamic methods to model fluid flow, species mass transport, and heat transfer in the TeSS. The FLUENT model of the TeSS in this study uses a model that was previously developed for ISS Crew Quarters studies in 1999. The FLUENT model of the Crew Quarters was modified for this study to reflect changes the TeSS configuration brought to the compartment structure and internal components such as a laptop computer, Portable Utility Light (PUL), etc. The development of the FLUENT TeSS model began in May, 2000 and the model was modified to reflect changes to the TeSS design received from NASA/Johnson Space Center (NASA/JSC) over the next four months. For example, NASA/JSC required that supply air to the TeSS be directed to various specific areas within the TeSS compartment from a 
single supply air register. This required implementation within the FLUENT model of a special supply register geometry and boundary conditions across the register. The development of the geometry and boundary conditions in the FLUENT TeSS model was also guided by the need to address several issues in regards to the ability of the model to simulate heat and mass transfer phenomena in the TeSS compartment accurately. For example, several of the scenarios considered for analysis included a TeSS configuration with the doors open to the TeSS. In order to model mass transfer accurately with this configuration, a simplified geometry of the ISS U. S. Laboratory was included in the FLUENT model to simulate the airflow outside as well as inside the TeSS. Heat transfer from the TeSS computer laptop and Power Utility Light required the inclusion of the computer laptop and PUL fans in the model in order to dissipate the heat properly to the TeSS compartment air. A radiation physical model was included in the FLUENT TeSS since previous studies indicated high surface temperatures are predicted for both the human and electronic equipment when radiation is not considered in the model. The thermal properties of the TeSS walls were also included in the model in order to simulate conductance through the walls. The TeSS walls include multiple layers of insulation (Nomex, Durrett, and Bisco Wrap) in addition to the structural material (Fibralam). Since simulation of species concentrations (i. e. carbon dioxide and water vapor) was required in this study, the FLUENT model includes a physical model which simulates species transport. Incoming species concentrations were specified as boundary conditions for both the supply air inlets and the human in the model. The geometry of the TeSS in the FLUENT model is depicted in Figure 1. and includes the following features:

-The aisle from the ISS United States (US) Laboratory with the associated air supply inlets (5) and outlets (6) (see Figures 3 and 4). Aisle hatches are closed.

-A 95 percentile male with a simulated metabolic rate (latent and sensible heat) and carbon dioxide respiration (see Figures 2 and 3 ).

-A laptop personal computer and Portable Utility Light (PUL) with associate heat loads during operation and simulated fan operation.

-The wall thickness and corresponding properties of the TeSS structure are included. The ISS aisle structure is considered adiabatic.
-The Crew Transfer Bags (CTB) are modeled in the TeSS geometry by modifying the shape of the curved back wall of the TeSS.

-The doors in the TeSS are simulated to allow for an open or closed position.

-The TeSS has outlets (2) located at the bottom of the TeSS bumpout section.

-An Audio Terminal Unit (ATU) is simulated in the TeSS bumpout section to allow for an open or closed position.

-The air supply inlet for the TeSS is configured to direct flow in 5 different directions (to the side, normal to the supply vent, parallel to the ceiling, and at the human's legs).

-The ISS LAB inlets use a perforated plate for a register. This inlet register is simulated in the model with a rectangular opening of equal flow area as the perforated plate.

In addition to the geometry described above in the TeSS FLUENT model, the following assumptions in regards to the physical models and boundary conditions are included in the TeSS model:

-A low Reynolds number turbulent flow regime is assumed due to the complex geometry of the TeSS. A standard k-e turbulent model is used.

-Radiation is considered significant and a Discrete Ordinates radiation model was used in the model with corresponding emissivities assigned to radiating surfaces.

-An outer surface temperature of $75(\mathrm{~F})$ is assumed for all exterior walls of the TeSS except for the bumpout wall. The walls of the ISS aisle are adiabatic.

-The latent metabolic load from the human is simulated as water vapor respiring from the person's mouth rather than as perspiration from the body surface.

-Mass flow rates are evenly distributed across the face of the TeSS air supply inlet. In order to maintain an equal mass flow distribution across the inlet face, flow other than normal to the inlet face will have a velocity greater than the velocity of flow in the normal direction. Velocity increases proportionally with the angle between the normal flow and the directed flow.

-Flow direction from the US Laboratory inlets (5) is assumed normal to the inlet face. 


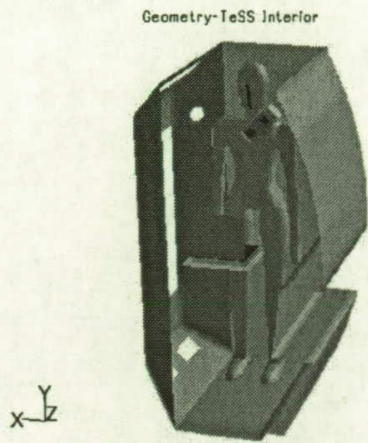

Grid $\quad$ Sep 25, 2000

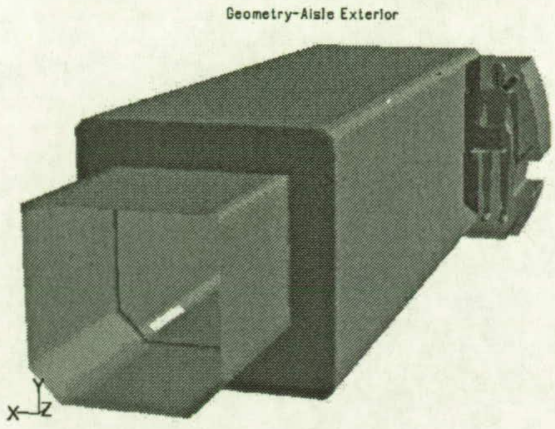

Grid FLUENT 5.4 (3d, segregaled, spe4, 200 )

Figure 1. TeSS FLUENT Model Geometry - Interior and ISS/US Laboratory Exterior View.

Boundary conditions for the five FLUENT TeSS models are described in Table 1. The boundary conditions for the steady-state cases include a nominal and cold or "sleep" case human metabolic load, with the TeSS doors open and closed. An additional "cold" steady-state case was simulated with the outlets blocked and the ATU open.

Five steady-state cases were simulated in the TeSS FLUENT model. Boundary conditions and TeSS configurations for the CFD cases are outlined in Table 2. Results for the CFD cases in terms of mean values for velocity, temperature, dew point, carbon dioxide concentration within the TeSS compartment are tabulated in Table 3. Results from the TeSS FLUENT model, which show local gradients for velocity, temperature, and carbon dioxide concentration and flow visualization are graphically depicted in Figures 2-6. for the steadystate cases.

- Figure 2. depicts the flow of air as it leaves the supply air vent with the doors closed and open for the cold case. The Crew Transfer Bags block the flow from the lower region of the cabin in the doors closed case. In the doors open case, the supply air appears to leave the cabin pre-maturely through the opened doors.

- Figure 3. depicts the local temperature and carbon dioxide concentrations in the cabin for the cold case, doors closed.

- Figure 4. depicts the effect of flow from the U.S. Laboratory supply vents on the TeSS when the doors are open, whereby flow enters the TeSS compartment through the lower region of the doors.

- Figure 5. depicts the local temperature and carbon dioxide concentrations in the cabin for the nominal case, doors closed.

- Figure 6.The Laptop and PUL fans re-circulate 60\% of the supply air flow within the TeSS in the nominal cases. Results show high velocity air circulating through the laptop computer and exiting through the back of the computer with accompanying warm temperatures as a result of convective cooling of the computer heat load. 

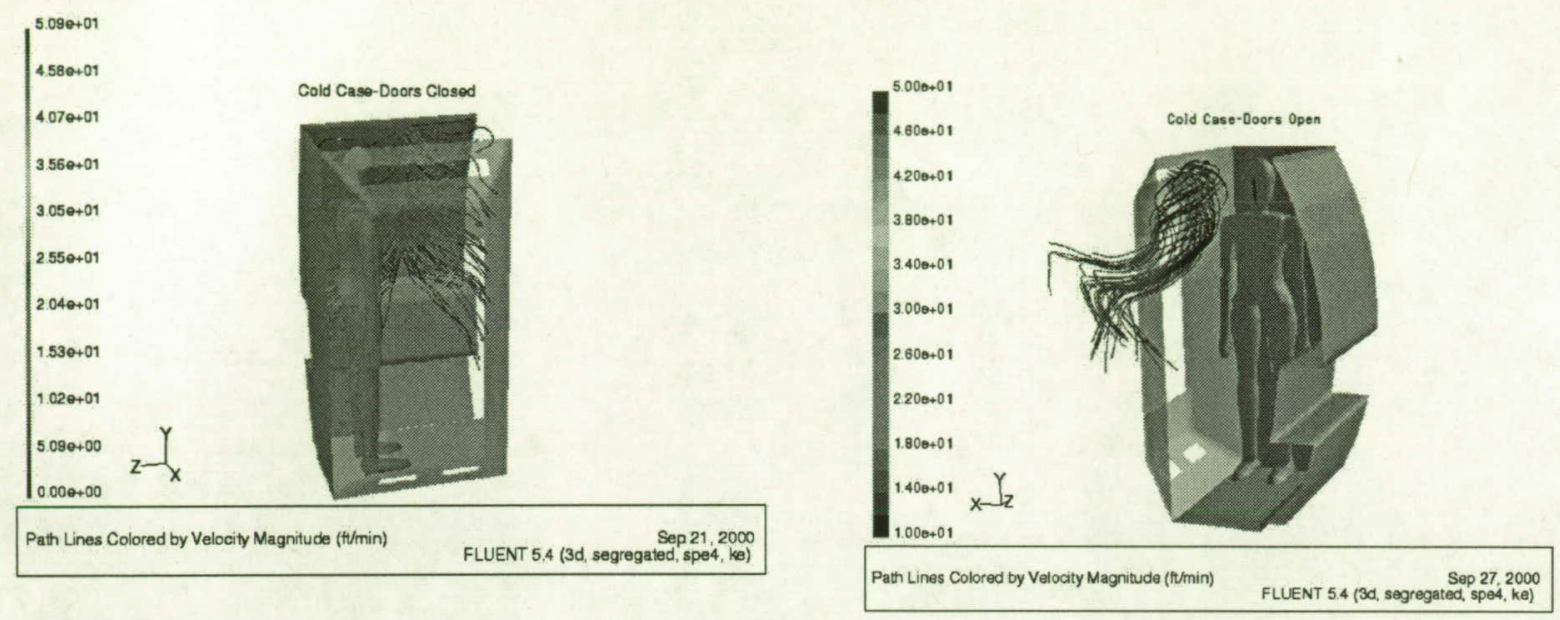

Figure 2. TeSS FLUENT Model Flow Characterization -Doors Closed and Open Respectively.
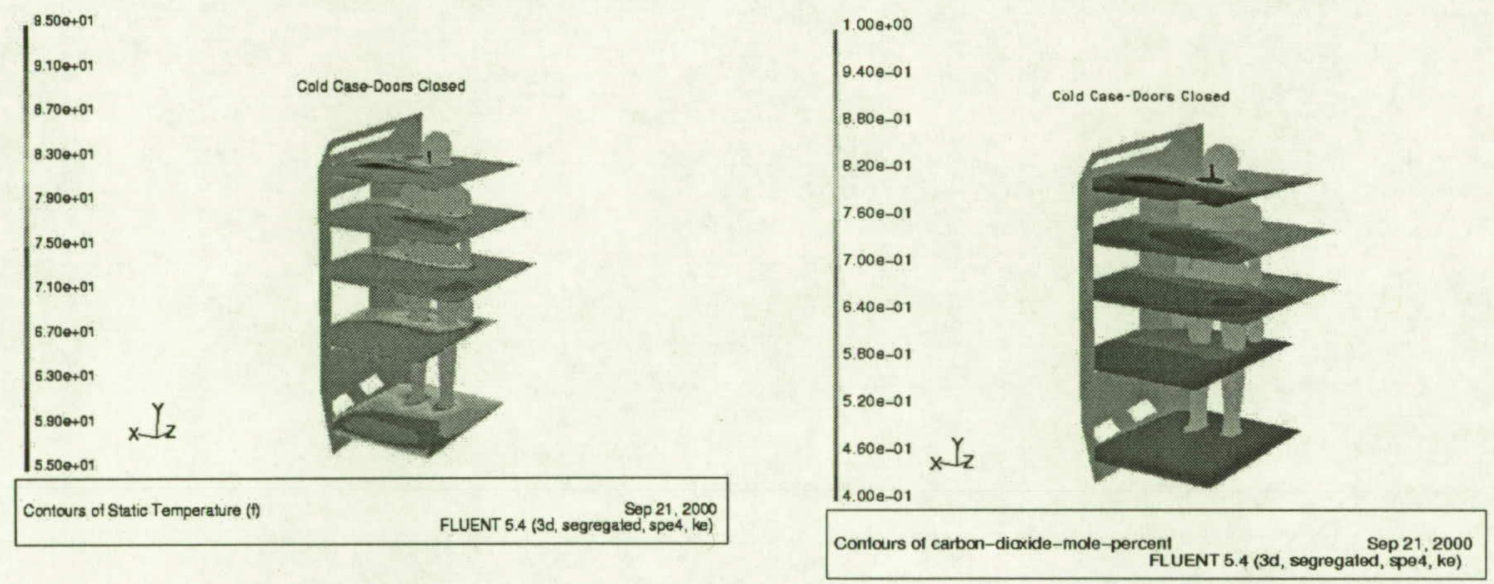

Figure 3. Cold Case (Doors Closed) TeSS Interior Temperature and $\mathrm{CO}_{2}$ Concentrations.
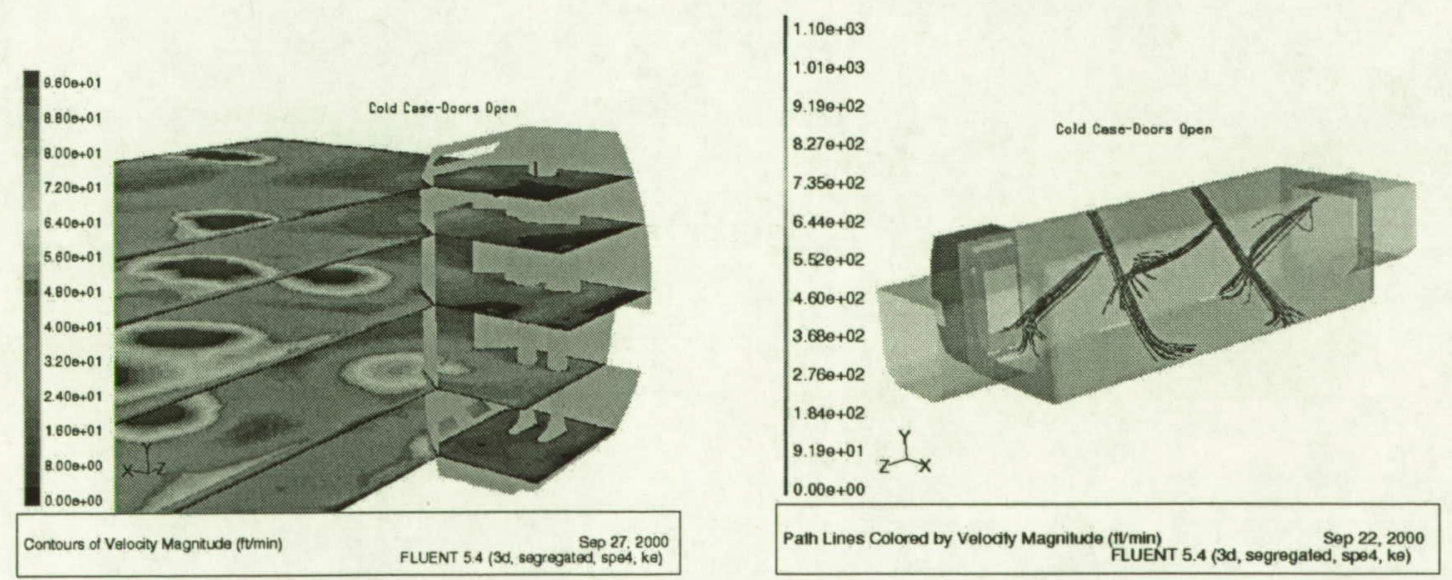

Figure 4. Cold Case (Doors Open) TeSS and U.S. Laboratory Velocity Gradients and Flow Characterization. 

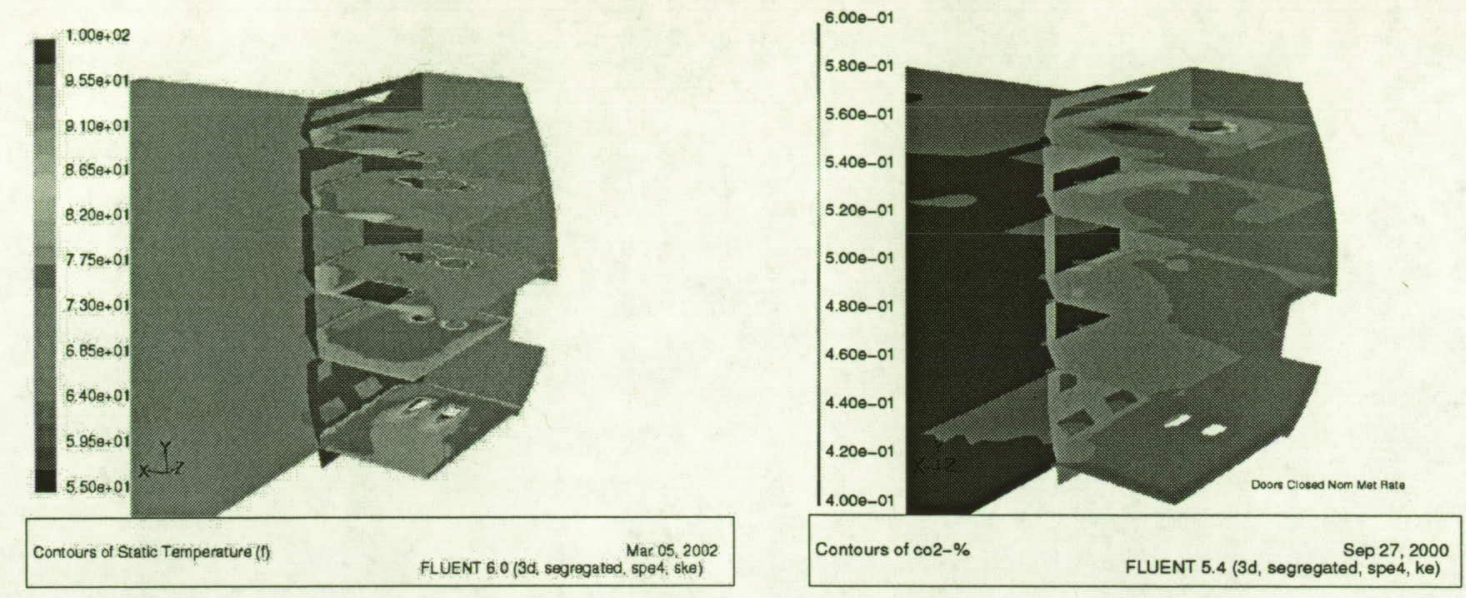

Figure 5. Nominal Case (Doors Closed) TeSS and ISS/US Laboratory $\mathrm{CO}_{2}$.
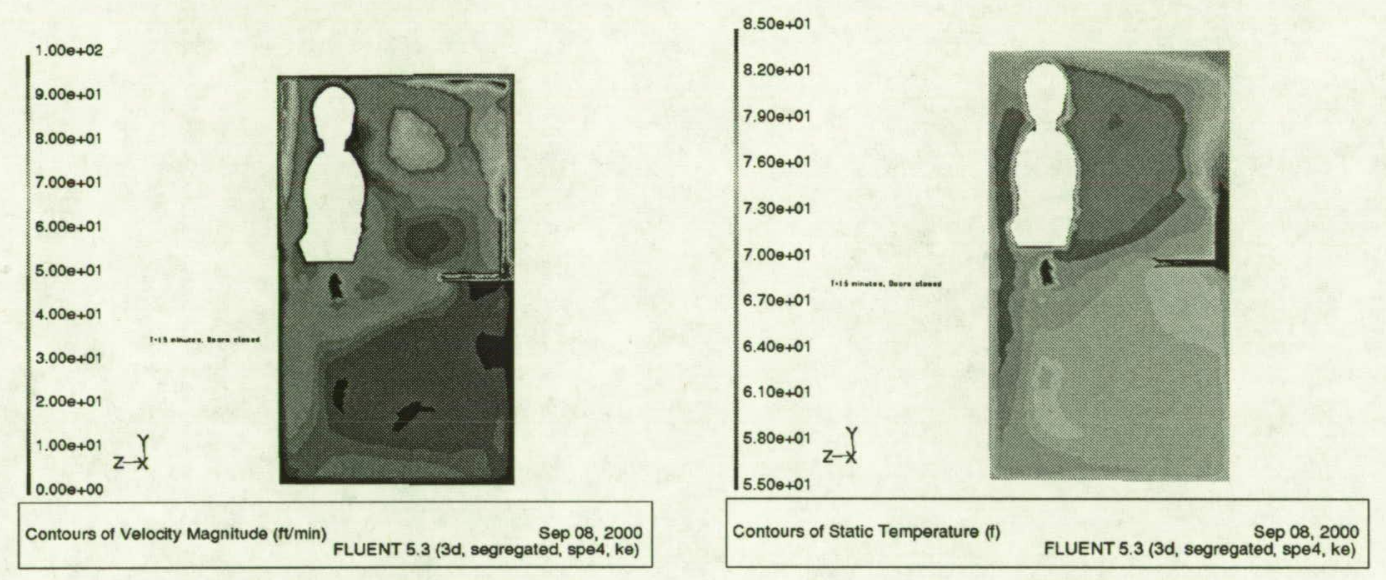

Figure 6. Nominal Case (Doors Closed) TeSS Local Velocity and Temperature - Vertical View.

One aspect of the model, which could be substantially improved, is the human model. Due to the limitations of the software, the simulation of carbon dioxide respiration and the sensible and latent heat load from the human is not modeled correctly. The human exhales carbon dioxide and water vapor in the model, however inhalation is not modeled. Secondly, water vapor from the skin surface is not modeled explicitly, but is "lumped" together with the water vapor respiring from the human's mouth. Simulation of the human latent heat load could be improved by modifying the software to enable the surface of the body to act as a source for water vapor and sensible heat. This feature could promote mixing of the water vapor in the surrounding air.
Comparisons can be made between the closed door G189A and CFD results for cases G3/F2 and G5/F5. For the sleep case comparison (G3/F2) both dry bulb and dew point temperatures were within 1 ${ }^{\circ} \mathrm{F}$, and the $\mathrm{CO}_{2}$ levels were the same. For the nominal case comparison (G5/F5) the difference was slightly more with the dry bulb difference being 2.3 ${ }^{\circ} \mathrm{F}$ and the dew points differing by $1.4^{\circ} \mathrm{F}$. Again the $\mathrm{CO}_{2}$ levels predicted by the two different tools for this case were almost identical. The comparison indicates that G189A with the metabolic man component can provide accurate volume-averaged results for temperature and species, leaving the determination of local variations to the CFD modeling tool.

\section{G189A / CFD Results Comparison}

\section{G189 - Initial Attempt at no-flow modeling}


The initial attempt at modeling a no airflow condition within TeSS involved the use of G189A. A model was created consisting of a cabin component, fan component, and a metabolic man component. Because any G189A model is set up as a flow loop, it 
is impossible to run the code without some kind of flow coming into the cabin. In this instance this was handled by maintaining a very small flow of air (less than 0.1 CFM) passing through the cabin. The analysis was started with an initial temperature of 75 ${ }^{\circ} \mathrm{F}$ within the cabin, a crewmember at a nominal metabolic rate, and an airflow rate of $35 \mathrm{cfm}$ coming into the cabin. The analysis was to determine the temperature and $\mathrm{CO} 2$ profile after the flow rate was reduced to near zero. The results showed the $\mathrm{CO} 2$ percentage increasing from $0.5 \%$ to $1.4 \%$ in 20 minutes, and the temperature increased from $75^{\circ} \mathrm{F}$ to over $90^{\circ} \mathrm{F}$ within 3 minutes. The temperature profile shown in Figure XX seemed to be too abrupt of an increase in such a short time, and further investigation showed that the large time step of 1 minute taken during this analysis caused the sudden temperature increase. Shortening the time step to 2 seconds resulted in a more believable result, extending the time it took to reach $90{ }^{\circ} \mathrm{F}$ from 3 minutes to approximately 12 minutes.

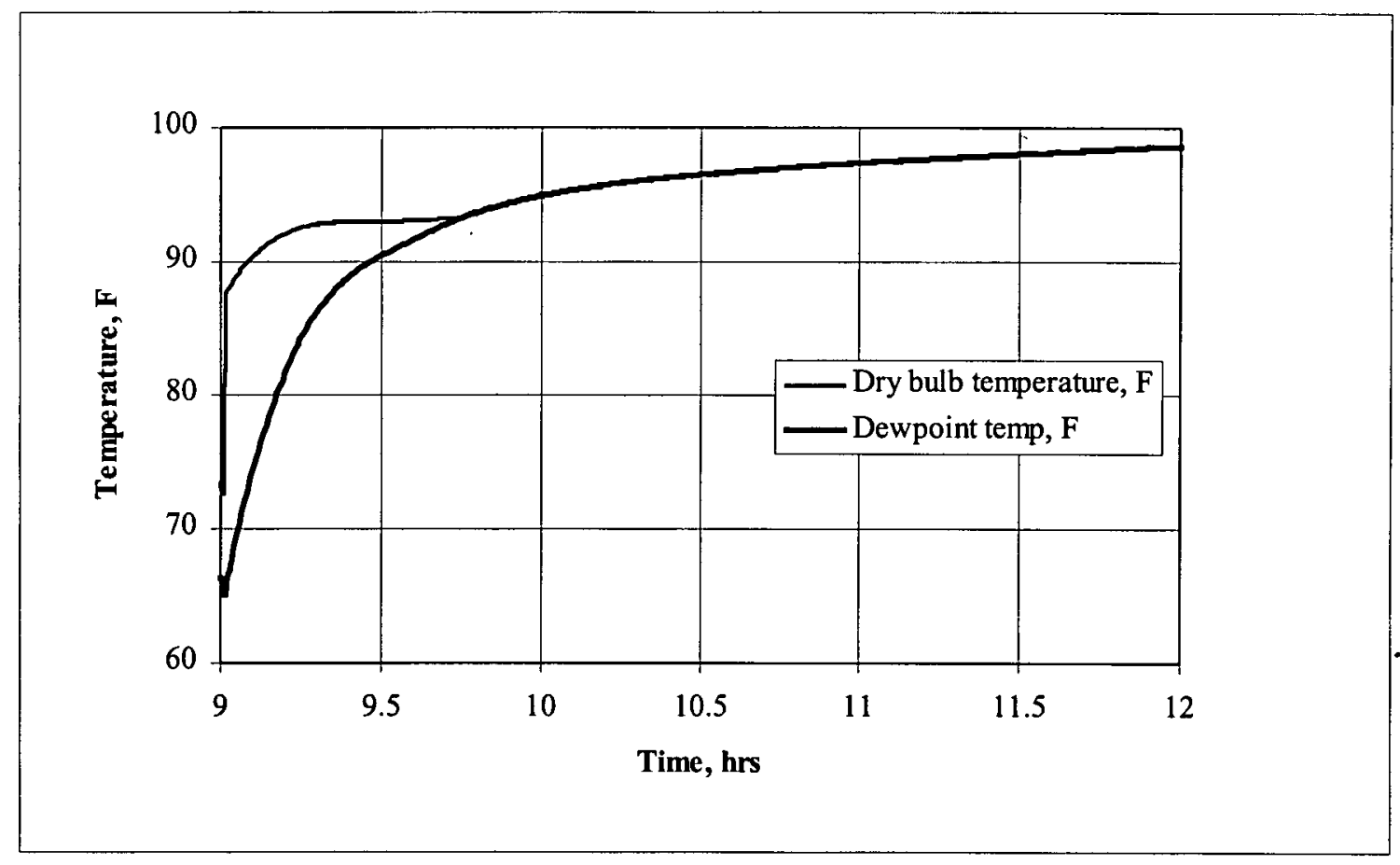

Figure 7. Initial TeSS No-flow G189A analysis results.

\section{Follow-on No-flow Simulation}

After modeling the nominal or design cases discussed so far, and taking a first cut at a no-flow model with G189A, the analysis team was tasked to either improve upon the G189A no-flow model or recommend another approach to the no-flow case .

As in the initial G189A no-flow analysis the goal was to determine the temperature, $\mathrm{CO}_{2}$, and humidity levels the crewmember would experience and at what rate would these parameters increase after the initiation of the failure. Because G189 assumes that the air inside the cabin component is well mixed it would not be a suitable tool for performing this analysis. The CFD model was the next logical choice to perform this analysis, however because of the size of the models running a transient case was beyond the capabilities of the simulation hardware. It was decided to use two modeling tools in conjunction to model the problem. An approach was used, whereby the cabin was divided into two separate volumes. One volume would represent the air volume the crewmember is breathing in and out of, and the other volume would represent the remaining dead air space in the compartment. First, FLUENT CFD software 
was used to determine the velocity profile inside the compartment due solely to the breathing rate of the human. From these results the approximate volume that the human is breathing into and out of was calculated. Second, a SINDA version of the 41-node man program (Reference 2) was modified to simulate a no airflow configuration using the CFD calculated volume as a FLUINT tank into which the human was breathing.

\section{CFD Model}

The first step in the analysis involved determining the approximate volume of air respired by the crew member. A minimum air velocity was used to determine the boundary of the volume. Volumetric flow rates from the crew member's mouth associated with various metabolic rates, are shown in Table 1.
These flow rates were obtained from the Bioastronautics Data Book (Reference 3) using an equation that determines breathing rates based upon metabolic rates.

Because these rates are average rates over one minute, the rates were doubled for this analysis to better match the velocity coming into or out of the mouth. These rates were then applied to a 2-D CFD model derived from the 3-D TeSS CFD model created previously. The plane shown in Figure 1 represents the space directly in front of the human, with the inlet boundary in the upper left hand corner of the rectangle representing the flow out of the mouth, and the outlet in the lower right hand corner of each rectangle. The plot shown here is a velocity contour plot for the $300 \mathrm{Btu} / \mathrm{hr}$ metabolic rate.

Table 4. Human Breathing Flow rates as a function of metabolic rate

\begin{tabular}{|c|c|}
\hline $\begin{array}{c}\text { Metabolic rate } \\
\text { Btu/hr }\end{array}$ & $\begin{array}{c}\text { Flow rate } \\
\text { Liters/minute }\end{array}$ \\
\hline 300 & 7.05 \\
\hline 450 & 10.57 \\
\hline
\end{tabular}

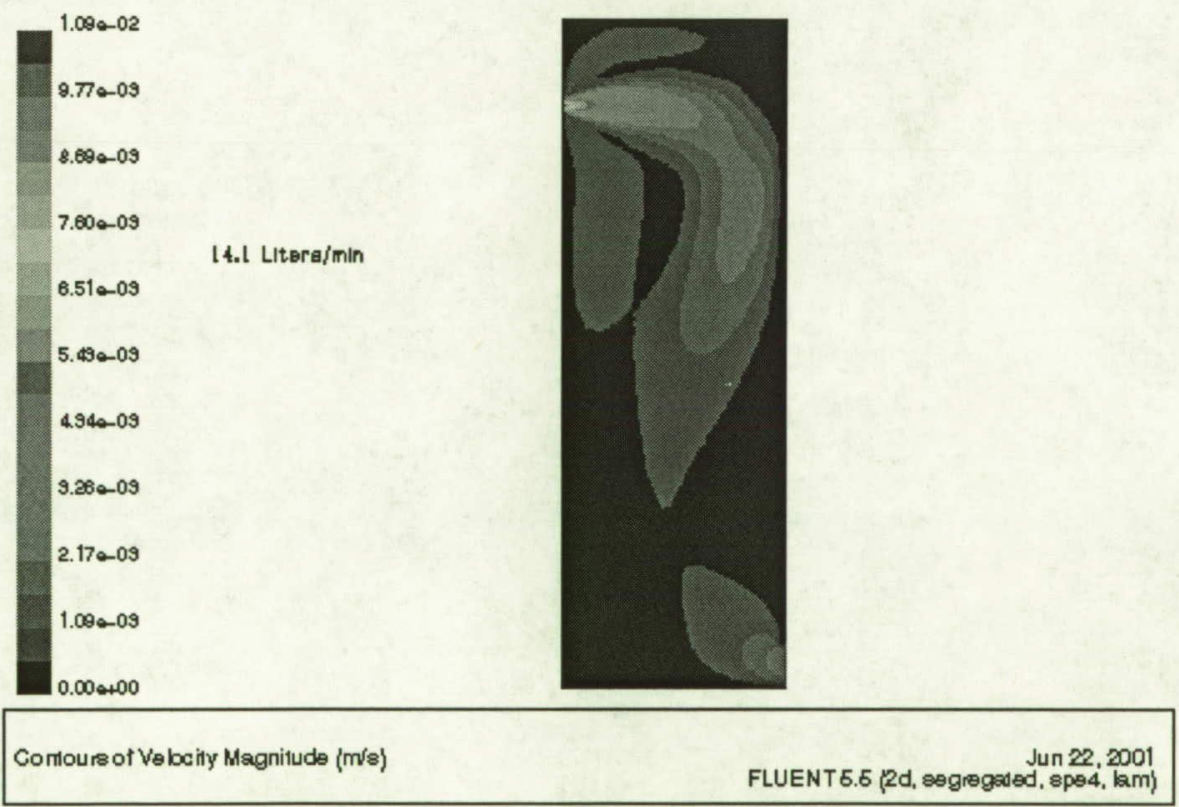

Figure 8. Velocity profile for $300 \mathrm{BTU} / \mathrm{hr}$ metabolic rate case.

From this contour plot the approximate volume of air that the human was breathing into and out of was calculated by hand. All areas where the velocity had decreased to below $10 \%$ of the inlet velocity were not included in this volume. This resulted in calculated volumes of $11.0 \mathrm{ft}^{3}$ for the $300 \mathrm{btu} / \mathrm{hr}$ case and 16.5 $\mathrm{ft}^{3}$ for the $450 \mathrm{btu} / \mathrm{hr}$ case. These volumes were used 
as FLUINT Tank volumes described in the next

\section{SINDA/FLUINT 41-Node Man Model}

The SINDA/FLUINT TeSS 41-node man model was an adaptation of the recently created 41-node man SINDA model (Ref. 2). This SINDA model was based upon the original 41-node man FORTRAN code. The original 41-node man model was a mathematical model of a human used to predict the human metabolic response in both a shirtsleeve environment as well as the response when the crewmember is in a suited mode. A condensed version of this code is used to model the human metabolic response in G189. Some modifications and additions were made to the SINDA model to better fit the scenario of no airflow around the human that was being modeled.

The 41-node SINDA model required some modifications for the no-flow case. Normally, the section.

model assumes there is convection heat transfer from the human surface nodes to the surrounding air. This convection heat transfer is based upon inputs from the user for the air velocity in the cabin, from which a surface heat transfer coefficient is calculated. These convection conductors between the human outer clothing surface and the cabin air were eliminated. In their place, the air around the human was divided into nodes connecting the human surface to the inner wall surface via conductors whose conductance values were based on conduction through still air. This nodalization can be seen in Figure 3. Between each 41-node man body surface node and the inner wall node there were three arithmetic nodes to allow conduction heat transfer between the human and the wall. The existing radiation conductors in the model were left unchanged connecting the human surface with the inner wall. The inner wall temperature in the model was fixed at a constant $75 \mathrm{~F}$.

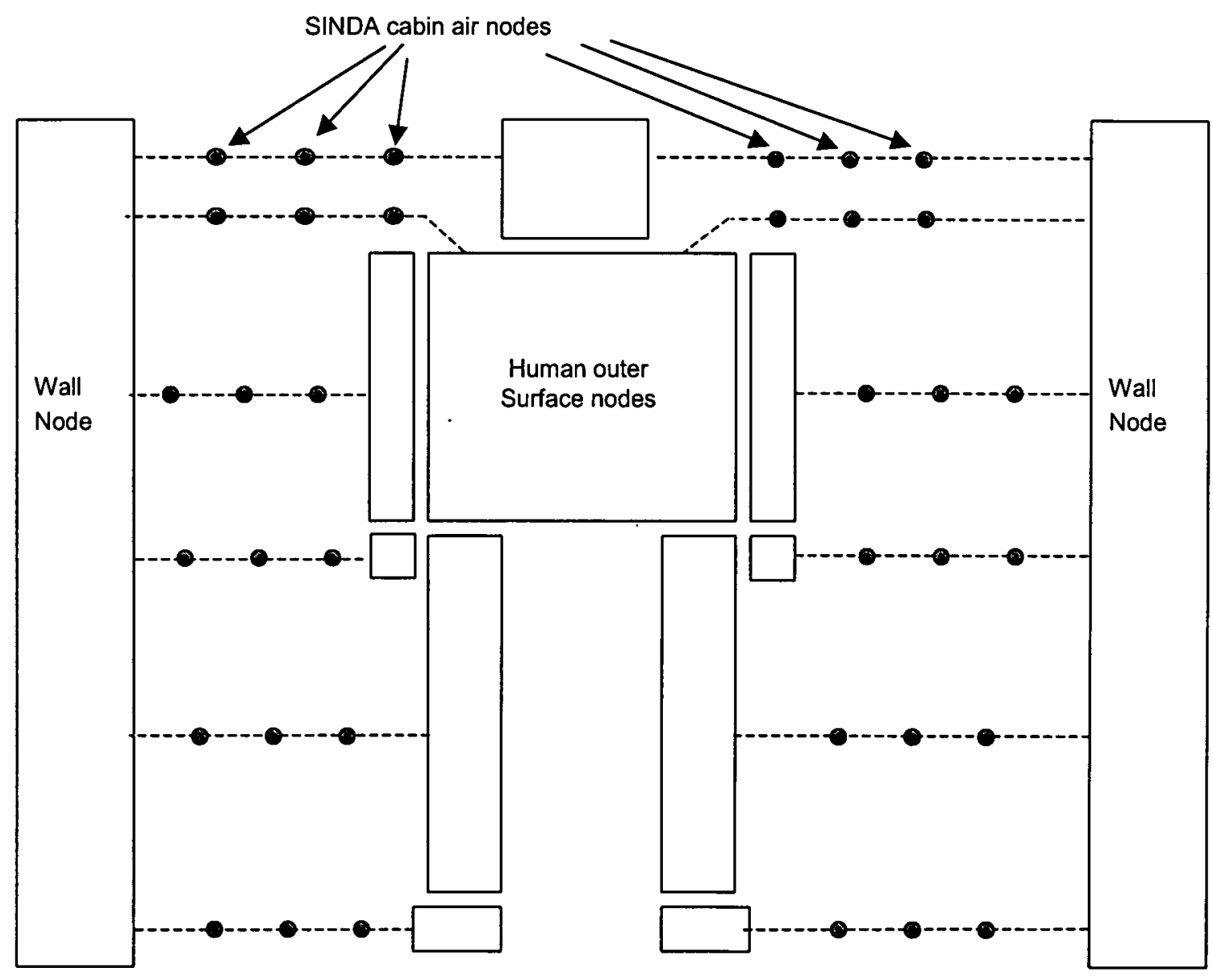


Figure 9. SINDA Nodalization for No-flow Model.

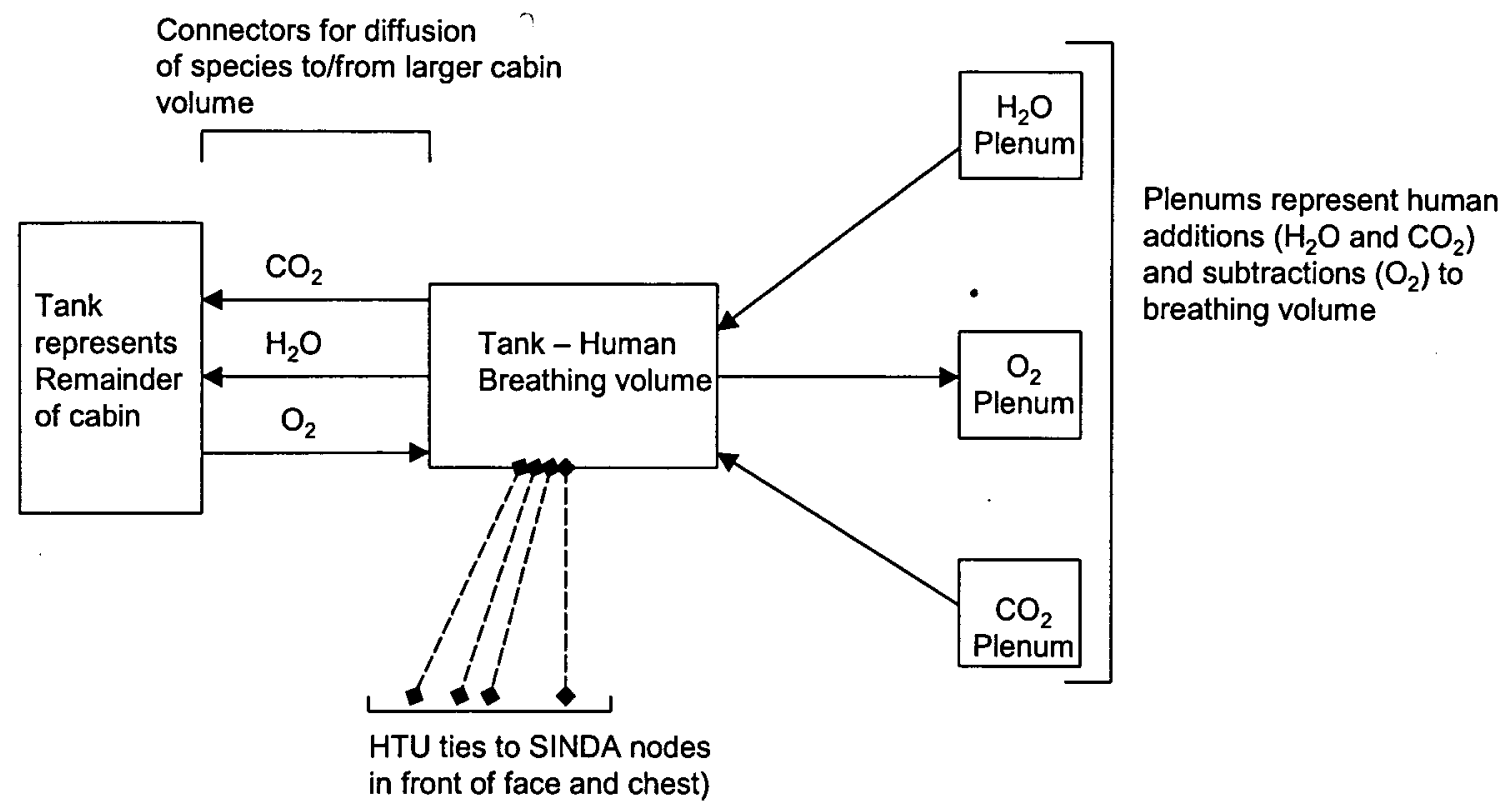

Figure 10. Modified SINDA/FLUINT Model Schematic.

The model also incorporated a FLUINT model, which is shown in Figure 4. The center tank in Figure 4 represents the air volume (calculated from the CFD results) that the crewmember is breathing in and out of. The net effect of this respiration is an increase in $\mathrm{CO}_{2}$ and $\mathrm{H}_{2} \mathrm{O}$ in the tank, and a decrease of $\mathrm{O}_{2}$. These three sources/sinks are represented by plenums which supply $\mathrm{H}_{2} \mathrm{O}$ and $\mathrm{CO}_{2}$ and remove $\mathrm{O}_{2}$ from the center tank. The 41-node man program calculated the flow rates between these plenums and the breathing volume tank. The other tank shown on the left side of Figure 4 represents the remaining volume of TeSS, and the model was configured to allow some mass transfer between the smaller breathing volume tank and this tank. In reality there is no hard barrier between these two tanks and species will diffuse from one to the other if the concentration in one volume is higher than the other. The mechanism for this transfer would be based upon diffusion only given the lack of any significant flow in the compartment. The flow rates between these tanks was based upon the principles of diffusion mass transfer of one species between two different mixture concentrations and was calculated using the following equation (Reference 4):

$N_{\mathrm{a}, \mathrm{x}}=\left(\mathrm{D}_{\mathrm{AB}} * \mathrm{~A}\right) / \mathrm{RT} *\left(\mathrm{P}_{\mathrm{a}, 1}-\mathrm{P}_{\mathrm{a}, 2}\right) / \mathrm{L}$
Where:

$\mathrm{N}_{\mathrm{a}, \mathrm{x}}=$ flow rate of species a due to concentration difference, $\mathrm{lbm} / \mathrm{hr}$

$D_{A B}=$ Binary diffusion coefficient of species, $\mathrm{ft}^{2} / \mathrm{s}$

$A=$ Diffusion surface area, $\mathrm{ft}^{2}$ (calculated from CFD results)

$\mathrm{R}=$ universal gas constant $\mathrm{ft}-\mathrm{lbf} / \mathrm{lbmole}{ }^{\circ} \mathrm{R}$

$\left(P_{a, 1}-P_{a, 2}\right)=$ Partial pressure difference of species at locations 1 and $2, \mathrm{lb} / \mathrm{ft}^{2}$

$\mathrm{L}=$ Diffusion length, $\mathrm{ft}$

The flow rates calculated using this formula were used to set the flow rates from the main cabin tank to the breathing tank. Because $\mathrm{CO}_{2}$ and $\mathrm{H}_{2} \mathrm{O}$ were increasing in the breathing tank, these diffused from the breathing tank to the main cabin tank, while $\mathrm{O}_{2}$ diffused in the opposite direction as it was being used up in the breathing tank. The FLUINT model shown in Figure 4 was tied to the SINDA model of Figure 3 using HTU ties between the breathing tank and the air nodes located near the face of the 41 -node man. These nodes represented the approximate location inside TeSS where the breathable volume existed, so it made sense to tie their temperatures closely with the Tank 1500 temperature. In the 41-node man logic the outlet breath temperature is calculated, and two nodes close to the face of the 41-node man were set to this value, so the breathing tank temperature matched very closely the outlet breath temperature. 
The temperature in the remaining TeSS volume represented by Tank 1001 was set equal to the

\section{Results}

The model was set up to run a one-hour transient simulation with the following initial conditions:

Initial air and wall temperatures:

$75 \mathrm{~F}$

Initial Human Core temperature:

$98.6 \mathrm{~F}$

Initial Human Heat Storage:

$0 \mathrm{Btu}$

Initial $\mathrm{CO}_{2} \%$ :

$.41 \%$

Initial Dew point Temperature:

$50 \mathrm{~F}$

Crew metabolic rate: $300 \mathrm{Btu} / \mathrm{hr}$ (sleeping) $450 \mathrm{Btu} / \mathrm{hr}$ (nominal activity)

Human clothing value:

1.0 average temperature of all the other air nodes shown in Figure 3.

Plots of the breathing volume tank dry bulb and dew point temperatures are shown in Figure 5 for both the $300 \mathrm{Btu} / \mathrm{hr}$ and $450 \mathrm{Btu} / \mathrm{hr}$ rate cases. Both cases reach fairly steady conditions of a $92{ }^{\circ} \mathrm{F}$ air temperature and $83{ }^{\circ} \mathrm{F}$ dew point temperature after one hour. The $450 \mathrm{Btu} / \mathrm{hr}$ results are slightly less than the $300 \mathrm{Btu} / \mathrm{hr}$ results because the volume calculated by the CFD model for this case was larger due to the higher respiration rate. This resulted in a larger Tank breathing volume tank that takes longer to heat up and longer to increase the moisture content.

(undergarment thickness/conductivity)

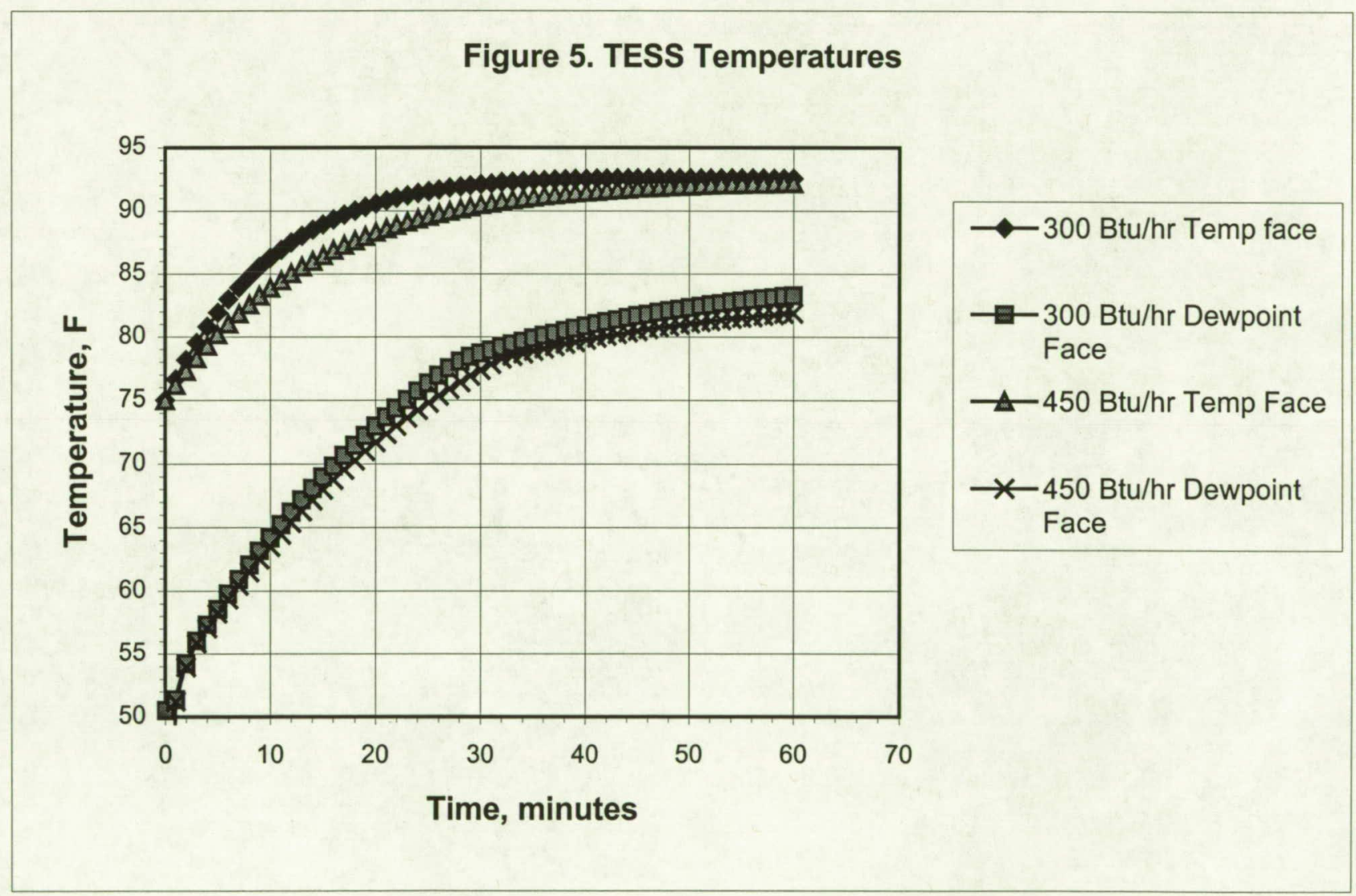

Figure 11. Title.

$\mathrm{CO}_{2}$ and $\mathrm{O}_{2}$ percentages are shown in Figure 6. The $\mathrm{CO}_{2}$ percentage reaches the upper ISS short-term limit on $\mathrm{CO}_{2}$ of $1.3 \%$ after approximately 13 minutes, while the $\mathrm{O}_{2}$ percentage decreases from an initial value of $21 \%$ to $15.7 \%$ after one hour. The upper
$\mathrm{CO}_{2}$ limit of $1.3 \%$ comes from the 1-hour limit stated in JSC 20584, "Spacecraft Maximum Allowable Concentrations for Airborne Contaminants". The rates of decay and increase for both species are almost identical for both metabolic rate cases. The 
higher $\mathrm{CO}_{2}$ production rate and $\mathrm{O}_{2}$ consumption rates of the $450 \mathrm{Btu} / \mathrm{hr}$ case are offset by the larger volume of the tank, so that the net increase or decrease worked out to be the same for the $300 \mathrm{Btu} / \mathrm{hr}$ case.

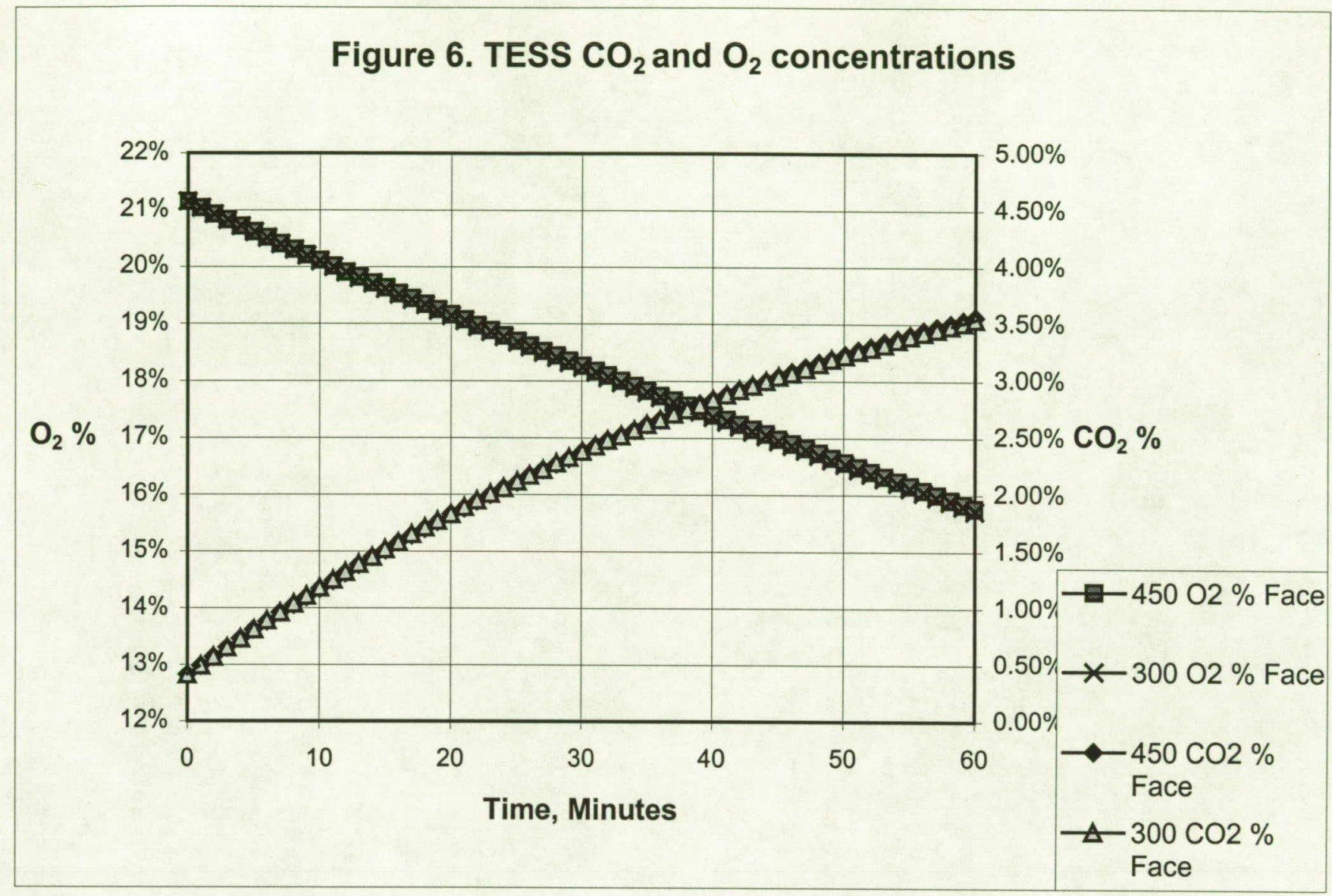

Figure 12. Title

The results of the TeSS thermal analysis did not conclusively indicate that the crew would wake up on their own accord before the $\mathrm{CO}_{2}$ concentration violated the ISS limit. The TeSS project team needed to determine if placing a temperature sensor in the supply air duct would indicate a temperature rise that could be used as a third independent control for a CCAA failure. To determine this response, the TeSS SINDA/FLUINT model was modified to include the last section of the supply air duct. The air duct was modeled as 15.2" x 12.55" x 3.0" which was connected to the LAB boundary by radiation. The air inside the duct was connected by air conduction to the nearest TeSS air node and the duct wall. The results indicated that the air temperature will rise from $55^{\circ} \mathrm{F}$ to $65^{\circ} \mathrm{F}$ within 6 minutes after the CCAA fails. 


\section{References}

1. Fluent, Inc., FLUENT 5 User's Guide, Volumes 1-4, July 1998.

2. Bue, G., "Computer Program Documentation 41-Node Transient Metabolic Man Program, Revised Document", LEC/672-23-030031, August, 1989.

3. Paul, T.H. "ISS Crew Quarters Analysis", EC2 Status review, February 3, 1999.

4. Paul, T.H. "Waste and Hygiene Compartment G-189A Analysis", MSAD-00-0368, June 23, 2000.

5. Reynolds, Chambliss and Keener "G-189AA Program Manual - Revision 1", CTSD-SH-327, February 17, 1987.

6. Webb, P."Bioastronautics Data Book”, NASA SP-3006, 1964.

7. Temporary Sleep Station Comfort Study Final Report, Brad Eckhardt, Tom Paul, November 2, 2000, MSAD-01-0053, Lockheed Martin Engineering and Sciences Company.

8. Fundamentals of Heat Transfer, Frank P. Incropera, David P. Dewitt, John Wiley \& Sons, 1981. 